\title{
53. Über die Biogenese des Carthamins, des roten Farbstoffs des Safflors
}

\author{
Von Mizu WADA \\ Research Institute for Natural Resources, Tokyo \\ (Comm. by Y. Asahina, M.J.A., May 13, 1953)
}

Die Blütenfarbe von Carthamus tinctorius(Linn.) ist nach Aufbruch der Knospe noch ein bis zwei Stunden gelb. Allmählich nimmt aber das Gelb eine Orange, dann orangerote und endlich rotbraune Tönung an und die Blüte verwelkt. Hervorzuheben ist, dass an beschädigten Stellen (etwa durch Bruch oder Zerquetschen) der gelben Blumenkrone rote Flecke entstehen, wobei der Farbstoff im Zellsaft aufgelöst vorhanden ist.

Zur Erklärung dieses Farbenwecksels habe ich die folgenden Experimente ausgeführt. Zunächst wurde es versucht, den Vorläufer des roten Carthamins zu isolieren und die Bedingung der Farbenwechsels festzustellen. Zur Entwässerung werden die Blütenblätter im Überschuss Azeton eingetaucht, pulverisiert, abgenutscht und getrocknet. Das so behandelte Material hält in trocknem Zustande lange Zeit unverändert.

Reibt man das so erhaltene Material mit Wasser im Mörser, so wird das Pflanzengewebe rot gefärbt. Wird das Material im Wasserstoffatmosphäre mit sauerstofffreiem Wasser behandelt und filtriert, so erhält man ein gelbes Filtrat, welches sich beim Einblasen von Luft sofort rot färbt. Durch Zusatz von einer Spur Na-diaethyldithiocarbamat und KCN wird das Rotwerden der obigen Lösung gehindert. Ebenfalls wirkt das Methanol farbwechselhemmend, wenn es zum Entwässerung der Blütenblätter angewendet wird.

Also kann man sagen, dass der Vorläufer des Carthamins wasserlöslich ist und durch Sauerstoff in Gegenwart eines Enzyms zum Carthamin *) übergeführt wird.

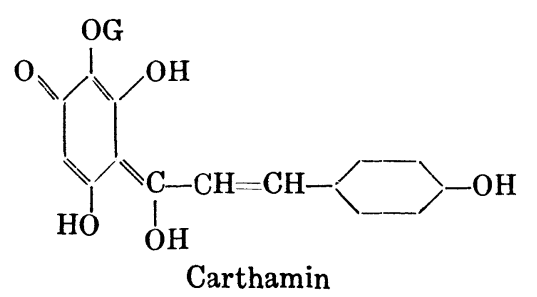

Früher bildete die Darstellung des Carthamins eine schwierige Aufgabe. Nur wurde es gefunden, dass das Carthamin in wasserhaltigen Azeton ziemlich leicht löslich ist, was die Reindarstellung des Carthamins aus Namabeni (das Rohcarthamin) sehr erleichtert.

*) Chika Kuroda: Scientific Paper of the Institute of Physical and Chemical Research, 13, 50 (1930). 
Zum Schluss möchte ich Herren Direktor Dr. Yasuhiko Asahina, Dr. Rikō Majima und Dr. Chika Kuroda, für Interesse und die Aufmunterung bei der Ausführung dieser Arbeit herzlichst danken. Auch Dr. Toyohiko Kawatani, dem Direktor der Plantage für Arzneipflanzen zu Kasukabe, für sein freundliches Entgegenkommen zur Verfügung gestellte Safflor, und Fräulein Tsuneyo Hattori, für die eifrige Mitarbeit an meinem Experiment spreche ich mein herzlichsten Dank. 